\title{
Latent Growth Model of Maternal Depressive Symptoms: Predictors and Effects on Infant's Developmental Outcomes
}

\author{
He Sook Kim*
}

Kyung Ja Park

Yonsei University

\begin{abstract}
The present study investigated the developmental pattern of Korean mothers' depressive symptoms from a week prior to birth through four months postpartum in a nationally represented survey sample in Korea, using a Latent Growth Curve model. Mother-reported four factors - maternal self-efficacy in parenting, father's participation in childcare, a number of hours mothers worked per week, child's emotional temperament-were examined as the predictors of depressive symptoms over time in the context of Korean culture. Effects of maternal depressive trajectories on their infants' developmental outcomes at the first year were also examined. Findings were as follows: First, mothers' reports of depressive symptoms decreased at the first month after birth and then increased again during the first 4 months postpartum. Second, mothers' perceived low spousal involvement in childcare, low parental self-efficacy, and their infants' difficult temperament at four-month old had significantly positive relations to the initial level of maternal depressive symptoms whereas the low spousal involvement in childcare and low maternal self-efficacy factors significantly predicted the changes of trajectories of maternal depressive symptoms. Third, the trajectories, in turn, predicted warm and responsive maternal parenting style at the fourth month. Subsequently, the parenting style had a significant longitudinal impact on the development of children's communication, problem-solving, and personal-social abilities. Based on these findings, awareness, preventive and interventional programs might be built to facilitate Korean mothers suffering severe postpartum depressive symptoms and further promote optimal early development of Korean children.
\end{abstract}

Keywords: Maternal pre-partum/postpartum depressive symptoms, maternal self-efficacy in parenting, paternal involvement in childcare, child's emotional temperament, mother's working hours, child development outcomes

\section{Introduction}

Depressive symptoms are commonly reported, especially among women of childbearing age (Downey \& Coyne, 1990). O'Hara and McCabe (2013) described postpartum depression (PPD) as "a common and serious mental health problem that is associated with maternal

* Corresponding Author: He Sook N. Kim, Department of Child and Family Studies, Yonsei University, 50 Yonsei-Ro, Seoul 120749, South Korea. E-mail: hesooknancy@gmail.com suffering and numerous negative consequences for offspring" (p.379). They estimated the prevalence of PPD to range from $13 \%$ to $19 \%$. Some studies have reported the prevalence of $12-$ month and lifetime PPDS was as high as 57\% (Halbreich \& Karkun, 2006). In Korea, the prevalence rates ranged from 20 to $25 \%$ (Ahn \& Kim, 2003; Yoon, 2011). Such high prevalence rates are alarming, given that maternal depressive symptoms during infancy have pervasive influences on the child's adjustment 
including delayed reactivity to stress, poor emotional regulation, and impaired cognitive development (Beebe et al., 2008; Cornish et al., 2005; Molfese et al., 2010). However, mothers' unawareness of their PPDS in the first year postpartum (Stone, 2013) and general social perception of PPD to be a normal stage in motherhood (Choi, Lee, Shin, \& Park, 2012) undermined and jeopardized the safety and healthy development of infants in Korea. In Korea, not many studies elucidated longitudinal changes of PPDS or explicated the effect of the trajectories of PPDS on the child development later time. Hence, better understandings of the trajectories of maternal depressive symptoms during the transition to motherhood and its consequences in child adjustment are of great public health significance.

\section{The Development of Maternal Depressive Symptoms}

The symptoms of PPD are loss of interest in the world around, no longer enjoying things that used to give pleasure, lack of energy, and feeling tired all the time (NHS UK, 2012). Other symptoms include sleep disturbance, having trouble with concentration and making decisions, low self-confidence, feeling very agitated or alternatively very apathetic, feelings of selfblame, and in severe cases, thinking about hurting oneself or others (NHS UK, 2012). These symptoms mirror those seen in major depressive disorder. Recently released Diagnostic Statistical Manual V (DSM-V) recognized "postpartum" major depressive episodes by adding severe anxiety and severe panic attacks while acknowledging the depressive episode may begin prior to the child's birth (APA, 2012).

The onset and duration of depressive symptoms, however, differ across studies. For instance, some studies indicated the depressive symptoms to begin from the pregnancy and prolonged even after the birth of child. Hay, Pawlby, Waters, and Sharp (2008) found that more than half of the women reporting postnatal depressive symptoms had been depressed during pregnancy as well. Specifically, the levels of depressive symptoms at the last trimester of pregnancy were significantly related to those of one week, two months, and six months postnatally (Luoma at el., 2001). But Cooper and Murray (1995) reported that most mothers tend to recover from the PPD by six months, whereas Campbell, Cohn, and Meyers (1995) indicated that a substantial proportion of mothers remain depressed one year after the childbirth. Depending on the design of studies, the severity and assessment-time of maternal depressive symptoms, onset, and duration varied from the time of pregnancy to the first year after the birth of children. In order to investigate changes of the depressive symptoms from the onset and duration of PPDS, Shin (2011) attempted to evaluate developmental trajectories of maternal depressive symptoms prior to and post the birth of infants.

Shin (2011) examined the developmental profiles of Korean mothers' depression a week prior to the childbirth, at four weeks and four months postpartum. Using the same data set from the Korean national survey as in the present study, she identified four different profiles of maternal postpartum depressive trajectories. The first group of mothers $(66.3 \%)$ demonstrated a mild decrease in depressive symptoms at first four-weeks and reported low degrees of the symptoms. The second group (24.4\%) showed a greater decrease at four weeks and had almost no depression symptoms. The third group $(8.1 \%)$ showed a mild increase in depressive symptoms at four weeks and reported moderate degrees of the symptoms. The last group $(1.2 \%)$ with a greater increase at four weeks suffered clinically high degrees of the symptoms. Shin's (2011) study took on a more person-centered approach. Therefore, no explanation on possible predictors and consequences of trajectories of maternal PPDS in infants' development is given. In order to obtain greater understandings on causal-effect relations between predictors and outcome variables of the changes in PDDS over time, a variable-centered approach, such as Longitudinal Growth Model (LGM), would be of great need. LGM is beneficial in that it is used in the 
Structural Equation Modeling (SEM) framework to estimate growth trajectory. The application of SEM in this study can provide greater awareness and predictability of the natural pathologic course due to interaction of the underlying culprit factors. The results of this study can render opportunities for appropriate counseling and intervention to take place for affected women and their family, subsequently for the betterment of infant's development.

\section{Peri-/ Post-partum Depressive Symptoms and Mother's Parenting Behaviors}

The continuity in depressive symptoms from pregnancy to postpartum periods is cited to presumably pose the significant implication in maternal psychological states and physiology (Hay et al., 2008; Davies et al., 2004). According to Beck (2001), for the mothers with prenatal depressed mood, possibility of occurrence of prolonged PPD increased to 5-6 times more than for those without (Bowen \& Muhajarine, 2006). Mothers with PPDS tended to be heavily burdened of caring for their newborns and in the states of head over heels in guiltiness, illogical thinking, anger, feeling of loss, etc. (Beck, 2001), ultimately shaping the mothers' depressed moods. Mother's depressed mood during pregnancy was linked to postpartum depressive symptoms at six months (Luoma et al., 2001).

In comparison studies, the depressed were less facilitative of social interactions, less adept in responding to their children's cues, and more likely to restrict their responses than nondepressed mothers when their children were distressed (Rutter, 1990). Instead, they respond in mechanical fashions much like robots and often were negligent of caring for the young (Lifeman, 2002). In a study on synchrony in mother-infant interactions, Field, Healy, Goldstein, and Guthertz (1990) observed depressed mothers spending more time in disengaged and protesting state, looking away and less time in play state. Mothers suffering mild PPDS expressed negative perceptions of their children's emotions and attention holding. They tended to report their infants as having more emotion deregulation and attention difficulties (Boivin et al., 2005). They, further, showed some disruptions in their parenting behaviors promoting healthy daily-routines in their children. McLearn, Miakovitz, Strobia, Marks, and Hou (2006) reported that mothers with postpartum depression at two to four months had reduced the odds of continuing breastfeeding, reading books, playing with and talking to infants, and keeping up with routines.

In cohort studies focusing on mothers with varied degrees of PPDS, mothers complaining about severe PPDS at six months were apt to interact with their infants still-faced (Lee, Chung, Lee, \& Gi, 2010). In the follow up study (Lee, Lee, Chung, \& Shin, 2011), mothers who scored high in PPDS at 6-8 month postpartum, interacted less positively, responsively, and expressively, but more intrusively with their infants.

In sum, these studies suggest that mothers with depressive symptoms are likely to provide poor parenting behaviors. Despite such adverse effects of both peri- and post-partum maternal depressive symptoms on their parenting styles, few studies have examined the impacts in framework and trajectories of depressive symptoms in conjunction with their predictors in Korea.

\section{The Predictors, Maternal Postpartum Depression, and Child's Outcomes}

Belsky's processing model (1984) of parenting identified three domains of personal psychological resources of parents, contextual/familial sources of stress and support, and characteristics of the child in shaping parental functioning in socialization of children. Accordingly, four predictors (mothers' selfefficacy, spousal involvement in caring for infant, the number of hours mothers employed, and infants' temperament) impacting the parenting system were explored in this study. As a factor of personal psychological resources of parents, mother's self-efficacy is often examined in a relation to effective maternal parenting (Bloomfield et al., 2005; Coleman \& Karraker, 
2000; Erdwins, Buffardi, Casper, and O'Brien, 2001; Leahy-Warren, 2005; Leahy-Warren, McCarthy, and Corcoran, 2011). Parental selfefficacy is parent's general beliefs of his/her ability to organize and carryout a set of tasks involved in parenting a child. The researches on mothers in the postpartum period reported a negative association between parental efficacy and maternal depression symptoms (Cutrona \& Troutman, 1986; Reece, 1992). Leahy-Warren et al. (2011) also reported that maternal parental self-efficacy is a significant predictor of postpartum depression at 6 weeks. Teti and Gelfand (1991) indicated that maternal parental self-efficacy was positively related to parenting competence while negatively related to depression after the delivery. Therefore, it is reasonable to assume that maternal self-efficacy would reduce mother's perceived depressive symptoms longitudinally. However, explanation of clear mechanism is needed to explain the effect of maternal efficacy on changes of maternal depressive symptoms.

Another area to study is contextual/familial resources. The familial resources of support, such as stress support, contribute indirectly and directly to improve parenting. Lack of familial resources or added stress accumulates the maternal depressive symptoms, eventually resulting in adverse parenting (Belsky, 1984). Recently birth-given-mothers relied frequently on spousal involvement in childcare, and it was considered as a strong protecting factor of maternal postpartum depression (Van Bakel \& Riksen-Walraven, 2002; Cutrona et al., 1986; Meyer, 1999; Mezulis, Hyde, \& Clark, 2004). Häggman-Laitila (2003) reported that mothers in postpartum period have reported the help received from their spouses, both with household chores and infant-care, to be of a great impact on their psychological well-being. It was found that mothers who perceived their husbands to be less involved in caring for young children suffered greater postpartum depressive symptoms (Fletcher, 2009). The recovery of mother's postpartum depression and self-esteem was shown to depend greatly on affection, and psychological and instrumental supports from her spouse in child rearing (Conenwett \& Wilson, 1983). Jung and Kim (2005) reported that the paternal parenting involvement had a significant effect on mothers' PPDS.

In regard to contextual sources of stress, the mother's working hours have been considered as a determinant of maternal depression (Kang \& Choi, 2001; Kim, 1999). According to Cho (1988), 22\% of mothers undergoing postpartum depression underpinned the conflict between family and work as a major reason for their stress. Since the employed mothers experienced more stress than the unemployed (Han \& Kwak, 2004), work-related stress is an important cause of postpartum depression (Kim, 2007). However, some research showed contradicting, positive effects of the maternal employment. The marital satisfaction in those employed was found to be much higher than that of the full-time housewife. It was thought because employed mothers were more likely to encounter opportunities to attain self-satisfaction, achievement and self-efficacy at their work, to be more content with the birth of children, enforcing greater emotional values on them, and to positively perceiving their parenting (Sohn, 2012). The low parenting stress in working parent may be due to alternative childcare supports the employed mother normally received in her absence, for example from grandparent or other care-taker. In 2013 national survey on childcare supports, $47.9 \%$ of mothers with 0-2 year-old children were relying on day-care centers while $54.5 \%$ of working mothers were assisted by either their own parents or parents-in-law in caring for their 0-2 year-old children (Ministry of Health \& Welfare, 2013). Working mothers of young children were found to emphasize more on the quality of time than on actual number of hours they spend with them (Kim \& Jang, 2008; Sohn, 2012). Those studies with opposing results investigated on the effects of mothers' employment of young aged from newborn infants to toddlers. So it would be of significance to find out the impact of mother's working hours in the period when maternal PPDS is at its peak. Instead of mothers' employment status, the self-reported hours employed would clarify the relationship between 
the maternal employment and depressive symptoms.

The temperament of child was reported to exert a significant link to the mothers' employment of the young aged from newborns since researchers have sought to determine the direction of effects between difficult child's temperament and parental depression (Cutrona \& Troutman, 2010). A growing number of evidences have supported that both directions exists and mothers of infants with difficulty temperament are at a greater risk of depression (Murray \& Cooper, 1997). It was reported that maternal depression and child's rhythmicity and attention persistence mutually affect each other (Kitamura, Sugawara, \& Shima, 1999). However, Cutrona et al. (1986), employing a path analysis, reported that infant temperamental difficulty was robustly associated with the parents' level of postpartum depression, both directly and through the mediation of parenting self-efficacy. Dodge (1990) found that difficult temperament of an infant posited as a cause of depression in a mother who became frustrated with helplessness of rearing a difficult child. On the other hand, more recently, Hanington et al. (2010) found the direction of effect from severity of maternal postnatal depression symptoms at 6 months to difficulty temperament of child at 12 months. These conflicting results could be explained by the time of assessment of child's temperament and mother's depression symptoms, and also by inclusion of interval provision of social supports. Other study had been reported social support having buffering effects against depression (Cutrona et al., 1986).

Maternal postpartum depressive states placed the depressed mothers at greater risk for providing poor parenting, which in turn, became an important contributor of unhealthy socialcognitive-communication development in infants. The quality of warm and responsive parenting directly exert on the development of communication, personal sociability, and problem solving in infancy, and infants learn to interact and respond appropriately to the environment. The growth of these abilities help infants to obtain comfort, support and attention or to otherwise meet their own needs, to humor themselves or to influence others, either positively or negatively (Warren, Denham, \& Bassett, 2008). Furthermore, they develop their personal social abilities to react appropriately to social signals such as facial, vocal or gestural cues of their important others during infancy. But it has been well evidenced that infants of mothers with postpartum depressive symptoms at six weeks showed disturbances in their attention sharing with their mothers (Beebe et al., 2008). During mother-baby interactions, infants of depressed mothers demonstrated less positive facial expressions and more negative facial expressions compared with infants of nondepressed mothers (Field, 1995). They demonstrated more gaze aversion (i.e., looking away), less vocalization (e.g., cooing, babbling, laughing), and lower activity levels. During free play, the infants of depressed mothers showed less exploratory play and less interest in playing with their mothers. Landry, Smith, and Swank (2006) attributed lack of social signal-reading and low activity in the infants to negative affection and low level of warm and responsive parental provisions. Warm sensitivity and willingness to meet the needs of infants by mothers during infancy was crucial to facilitate the development of social skills. Responsive parenting behaviors promoted joint engagement and reciprocity in the parent-child interaction and helped children learn to take a more active and independent role in problem-solving during toy-play in subsequent years. Also mother's increased use of contingent responsiveness and verbal encouragement improved children's cooperation; by mother's more frequent use of maintaining child's attention on their interests and labeling objects, children's ability to use words to communicate with mothers improved (Landry, 2008).

\section{The Present Study}

Many studies have focused either one of two key sets of relations posited in the basic model of environmental transmission of maternal depression: (a) Determination of predictors of 
depression and which in turn leads to disruptions in parenting, and (b) these parenting and family disruptions lead to maladaptive outcomes in the child (Dodge, 1990). However, few studies have examined both aspects simultaneously. The present study extends the previous literature by first exploring the trajectories of depressive symptoms from the first week prior to through a year after the birth; second, by elucidating the predictors of these trajectories at four months; and lastly, by investigating whether those predictors lead to parenting behaviors at four months and kids' first-year-social, cognitive, and communication development indirectly through the maternal depressive symptoms.

\section{Methods}

\section{Participants}

This study employed the data from the Panel Study of Korean Children (PSKC) ${ }^{1}$, carried out in 2008 and 2009 by Korea Institute of Child Care and Education (KICCE). The sample of the panel study consists of families of newborn infants delivered from April to July 2008 in nationwide Obstetrics and Gynecology clinics. Using a multi-stage, stratified sampling system, $\mathrm{OB} / \mathrm{GYN}$ clinics with 500 or more cases of parturition in the year of 2006 were first screened from six districts in Korea. Then from each district, a specific number of delivery cases were proportionally allocated. The subjects were phoned to participate in the study and consents were obtained. From 2,561 recruited families, 2078 (81.1\%) families participated in 2008 PSKC. In the following year, 1,904 (91.6\%) families remained in the study along with newly recruited 52 families, resulting in a total of 1956 families. There were no same sex couples or inter-racial marriages.

The mean age of children at the fourth month was 5.3 months old (ranged 4 to 10 months old, with $S D=1.20)$. Mothers and fathers had the mean ages of 31.3 months old (ranged 19 46

\footnotetext{
1 For more information refer to the site of PSKC at http://panel. kicce.re.kr/kor/index.jsp
}

years old, with $S D=3.72$ ) and 33.9 months old (ranged 19 51 years old, with $S D=4.04$ ) respectively. The families had been married for average duration of 49.5 months (ranged 6.00 239 months, with $S D=36.70$ ) and had average monthly income of 3,211,400wons (ranged 0-13,000,000wons, with $S D=1,497,100$; $\$ 1.00=1,100$ wons). Average monthly income of a person in Korea is 3,240,000wons (Choi, 2012).

Of the educational background of mothers who responded to this section of survey, $30.90 \%$ of mothers had graduated from high school or less, $28.70 \%$ had completed 2 or 3 -year colleges, $34.80 \%$ had graduated from universities, and $5.60 \%$ were either attending or had completed graduate programs. Among fathers, 28.70\% had graduated from high school or less, $21.00 \%$ had completed 2 or 3-year colleges, $40.30 \%$ had graduated from universities, and $10.10 \%$ were either attending or had completed graduate programs.

Regarding employment status of parents, $0.4 \%$ of both mothers and fathers were attending schools, and $31.60 \%$ of mothers and $98.4 \%$ of fathers were employed.

\section{Procedure}

The Panel Study had two major data collections in 2008 and 2009 (at four months and at 12 months postpartum), along with two minor early waves for prenatal depression (a week prior to the birth) and postpartum (a month postpartum). Hereafter, the times of assessments are to be referred as Wave 1(the week prior to the birth), Wave 2 (a month post), Wave 3 (four months post), and Wave 4 (12 months post). From January to December of 2008, Wave 3 data were collected via structured questionnaires and child's development screening test (The Korean-Ages \& Stage Questionnaires: K-ASQ; Heo, Squires, Lee, \& Lee, 2006). The questionnaires for mothers and fathers were first mailed and investigators visiting homes for KASQ tests. The interviews were carried out in the method of Computer-Assisted Personal Interviewing (CAPI) to mothers or main caretakers or the kinship of the infants. From 
June to October 2009, in the same manner as the previous year, Wave 4 assessment was conducted from mothers (or the main caretakers) via home-visit-interviews and mailed-surveyquestionnaires.

\section{Measures}

Child's Developmental Outcomes. The Korean-Ages \& Stage Questionnaires, $2^{\text {nd }}$ edition (K-ASQ; Heo, Squires, Lee, \& Lee, 2006) was used to assess the developmental outcomes of children at Waves 3 and 4. It was developed as a screening test for young children aged 4 to 60 months to examine five developmental areas: communication, gross motor, fine motor, problem solving, and personal- social development. Each area contains six items, totaling 30 items. Parents reported on a 3 point Likert-type Scale ranged from Yes (10, infant's target behavior is observed), Sometimes (5, beginning to be observed), to No ( 0 , cannot carry out the behavior yet). The possible score ranged from 0 to 60 in each area. This study used the three of the sub-scales in the areas of communication, problem solving, and personal social abilities. Cronbach alphas for these subscales were $.75, .72$, and .65 , respectively.

Maternal Parenting Style. Mothers reported on their interaction styles with their infants when the infants were 20-month-old. Six items of the social interaction subscale of the Parental Style Questionnaires (PSQ, Bornstein et al., 1996) were used in this study, comprised of affective and responsive parenting behaviors. The scale was a 5 point Likert-type Scale $(1=$ not at all to $5=$ very much so), thus total scores ranged from 6 to 30 . Cronbach alpha was .82 .

Maternal Depression. The Kessler's Depression Scale (K6; Kessler et al., 2002) was used to assess the depression that mothers experienced from the prenatal to postnatal periods. The scale was adapted from the Structured Clinical Interview Instrument for DSM-IV and included six items of mother-self reports on a 5 point Likert-type Scale $(1=$ Never feel that way to 5=Always feel that way). Cronbach alphas for the scales on depressive symptoms were $.82, .81$, and .91 for Waves 1,2 , and 3 , respectively. Total scores ranged from 6 to 30 , with higher scores presenting severer degree of maternal depression.

Mother's Self-Efficacy. The Pearlin SelfEfficacy Scale (Mainieri \& Grodsky, 2006) was used to assess mother's overall sense of control over her life and effectiveness of parenting when the infants were 4-month-old. Mothers reported their self-efficacy with the four items on a 5 point scale $(1=$ Not at all to $5=$ Very much so $)$. The total scores ranged from 4 to 20 points, with higher scores representing higher levels of maternal self-efficacy. Cronbach alpha was .81.

Father's Involvement in Child-rearing. Mothers reported on the paternal involvement in child-caring on The Father's Trait Scale (Kang, 1993) during the first year. It consists of four items on a 5 point Likert-type Scale. The possible range of scores runs from 4 to 20, with the higher scores representing higher levels of fathers' involvement in child-rearing, perceived by mothers. Cronbach alpha for Wave 3 was .77.

Mother's Weekly Working Hours. After indicating mother's employment status, employed mothers responded to an open question: "How many hours a week do you work?" Those who were non-employed were considered to work "zero" hour for this part.

Child's Temperament. The child's trait was assessed, using the Temperament Survey for Children-Parental Ratings, Emotionality, Activity, and Sociability (EAS; Buss \& Plomin, 1984). For this study, 10 items from the emotionality and activity subscales were used. Mothers reported on a five point Likert-type Scale (1=Never so to $5=$ Very much so), total score ranging from 10 to 50. Higher scores indicated higher levels of temperamental difficulties of the child during infancy. This study utilized the emotionality subscale only and its Cronbach alpha was .77. 


\section{Statistical Analyses}

The analyses for the present study were twofolds. First, we employed Latent Growth Curve (LGC) modeling using Mplus 6.1 (Muthén \& Muthén, 1998) to examine changes in mothers' depression across the three time-points (Wave1: a week peripartum, Wave2: the first month, and Wave3: four months postpartum). The mothers' ratings on the depression scale were used to estimate two latent factors (intercept and slope). The intercept factor represents the initial level and the slope factor represents the rate of changes in maternal depression over time. This allowed us to examine prospective predictive patterns of the predictors. Thus, the intercept factor can be interpreted as the estimated level of maternal depression at Wave 3. The LGC model was first fitted without predictors to examine overall patterns of maternal depression over time. Second, predictors were then added to examine how the mother's reported self-efficacy and perceived levels of father's involvement in childrearing, mother's weekly working hours and child's emotional temperament at Wave 3 related to changes in maternal depression. In addition, mothers' parenting behavior at Wave 3 , and the child's outcomes of social development were added to the model to examine how developmental trajectories of maternal depression were related to mothers' parenting behavior and subsequently to the child's adjustment at 12 month-old. The child's developmental outcome-measure consists of communication, problem solving, and personalsocial ability assessment at twelve month postpartum period (Wave 4).

\section{Results}

\section{Descriptive}

The means ( $S D$ 's) for maternal depression across the three waves were 1.90(6.60), 1.50(.60), and 1.95(.70) (Table 1). This suggests that maternal depression tends to decrease at the first month after birth and then increase again during
Table 1

Means and Standard Deviations for Variables

\begin{tabular}{lclc}
\hline \multicolumn{1}{c}{ Variables } & $N$ & Mean & $S D$ \\
\hline $\begin{array}{l}\text { Mother's Self-Efficacy } \\
\text { Father's Involvement in }\end{array}$ & 1858 & 3.78 & .68 \\
childcare & 1860 & 3.58 & .81 \\
$\begin{array}{l}\text { Mother's Wkly Work } \\
\text { Hrs }\end{array}$ & 626 & 43.89 & 12.37 \\
Child Temperament & 2076 & 2.71 & .61 \\
Emotion & & & \\
Maternal Depression: & & & \\
$\quad$ MaternalDepression1 & 2073 & 1.90 & .66 \\
MaternalDepression2 & 1635 & 1.50 & .60 \\
$\quad$ MaternalDepression3 & 1853 & 1.95 & .70 \\
Maternal Parenting & 1863 & 4.05 & .50 \\
Child: & & & \\
Communication & 1903 & 8.20 & 1.88 \\
Problem Solving & 1903 & 8.25 & 1.98 \\
$\quad$ Personal Social & 1903 & 8.75 & 1.82 \\
\hline
\end{tabular}

the first 4 months postpartum.

In general, average depression scores for new mothers in Korea fall in the range of normal and mild depression (0-2). The rates of mothers with severe postpartum depression symptoms who scored 3 or more are $5.10 \%$ at Wave $1,2.40 \%$ at Wave2, and $6.50 \%$ at Wave3 (Table 2).

Correlations among predictor-variables and three time-point measures of maternal depression are presented in Table 3. Overall, the maternal depression was significantly correlated with mother's self-efficacy, father's involvement in childrearing, and child's emotional temperament, and the scores on maternal parenting style at four months. It was also significantly correlated with child's communication $(r=.10, p<.01)$ problemsolving $(r=.05, \quad p<.05)$, and personal-social $(r=.09, p<.01)$ scores in the first year. Mother's parenting style consisting of warm and responsive behaviors in child nurturing, and the two parenting patterns were distinctively related to each area of child's socio-emotional development. The scores on mother's warm parenting was significantly correlated with the scores of child's communication $(r=.10, p<.01)$ 
Table 2

Numbers of Mothers in Each Depressive Symptoms Groups

\begin{tabular}{cccc}
\hline Three Levels of & Wave1 & Wave2 & Wave3 \\
Depressive Symptoms & $N(\%)$ & $N(\%)$ & $1 \%)$ \\
\hline Normal(1-2.17pt) & $1528(73.70)$ & $1447(88.50)$ & $408(22.00)$ \\
Mild/Moderate(2.18-3.00) & $440(21.20)$ & $149(9.10)$ & $120(6.50)$ \\
Severe(3.01-5.00) & $105(5.10)$ & $39(2.40)$ & $1853(297.0)$ \\
\hline$N($ missing) & $2073(77.0)$ & $1635(515.0)$ & \\
\hline
\end{tabular}

Table 3

Correlations with All Variables

\begin{tabular}{|c|c|c|c|c|c|c|c|c|c|c|c|}
\hline Variables & 1 & 2 & 3 & 4 & 5 & 6 & 7 & 8 & 9 & 10 & 11 \\
\hline \multicolumn{12}{|l|}{ Mother's Self-Efficacy } \\
\hline Father's Involvement & $.18^{* *}$ & & & & & & & & & & \\
\hline Mother's Wkly Work Hrs & -.01 & .01 & & & & & & & & & \\
\hline $1^{\text {st }}$ Child Temperament Emotion & $-.21^{* *}$ & $-.04^{* *}$ & .04 & & & & & & & & \\
\hline \multicolumn{12}{|l|}{ Mom's Depression: } \\
\hline MaternalDepression1 & $.26^{* *}$ & $-.12^{* *}$ & -.03 & $.13^{* *}$ & & & & & & & \\
\hline MaternalDepression2 & $-.21^{* *}$ & $-.08^{* *}$ & -.02 & $.11^{* *}$ & $.25^{* *}$ & & & & & & \\
\hline MaternalDepression3 & $-.55^{* *}$ & $-.20^{* *}$ & -.02 & $.21^{* *}$ & $.38^{* *}$ & $.31^{* *}$ & & & & & \\
\hline \multicolumn{12}{|l|}{ Maternal Parenting: } \\
\hline Warm & $.23^{* *}$ & $.20^{* *}$ & .03 & $-.06^{* *}$ & $-.07^{* *}$ & $-.06^{*}$ & $-.22^{* *}$ & & & & \\
\hline Response & $.28^{* *}$ & $.22^{* *}$ & .01 & $-.14^{* *}$ & $-.11^{* *}$ & $-.10^{* *}$ & $-.26^{* *}$ & $.63^{* *}$ & & & \\
\hline \multicolumn{12}{|l|}{ Child Development: } \\
\hline Communication & .03 & .04 & $-.10^{*}$ & -.01 & -.01 & -.01 & -.04 & $.10^{* *}$ & $.07^{* *}$ & & \\
\hline Personal Social & $.08^{* *}$ & .02 & -.06 & $-.05^{*}$ & -.02 & .02 & $-.11^{* *}$ & $.08^{* *}$ & $.09^{* *}$ & $.39^{* *}$ & \\
\hline Problem Solving & .04 & .02 & .00 & -.02 & -.04 & .03 & $-.05^{*}$ & .04 & $.05^{*}$ & $.39^{* *}$ & $.43^{* *}$ \\
\hline
\end{tabular}

and personal social ability $(r=.08, p<.01)$ while the responsive parenting with child's communication $(r=.07, p<.01)$, problem solving $(r=.05, p<.05)$, and personal social ability $(r=.09$, $p<.01)$.

\section{Developmental Trajectories of Maternal Depression}

As indicated in the mean scores, maternal depression decreased at a month postpartum suggesting that the overall pattern might not be linear. Therefore, both a linear growth model and a linear spline growth model (Stoolmiller, 1995) were tested to determine the baseline model that captures the developmental pattern of maternal depression across Wave 1 to Wave3. In the linear growth model, the intercept factor loadings were all fixed at 1 , and the slope factor loadings were fixed at $-.32,-.3$, and 0 , to correspond with Wave 1, Wave 2, and Wave3, respectively. So the coefficients were determined 
by transforming months into year-unit and subtracted it from four month. As expected, the linear model did not fit the data well, $\chi^{2}(3)=441.74, p=.00, C F I=.10, T L I=.09$, and $R M S E A=0.27$. We then fitted the linear spline model in which the intercept factor loadings were all fixed at 1 and the slope factor loading at Wave 2 and 3 was fixed at -.3 , and at 0 , respectively, and Wave 1 was freely estimated. The linear spline model had a significantly better fit, $\chi^{2}(1)=5.73, p=.01, C F I=.99, F L I=.97$, and $R M S E A=.04$. By freeing one parameter, the chisquare statistic was reduced from 441.74 to 5.73, nested $\chi^{2}=436.01, d f=1, p<.001$, which indicated a significant improvement of the fit of the linear spline model over the linear growth model; thus, the linear spline model was used in the remaining analyses.

The means of the intercept and slope factor in the unconditional linear spline model were 1.95 $(p=.00)$ and $1.46(p=.00)$, respectively, indicating that both were significantly different from zero. These values represented the average initial levels and growth rates across in the sample. The intercept factor had significant variance of .19 $(p=.00)$ while slope factor had the variance of .63 $(p=.066)$, respectively. These variances represented the individual variability in the initial level and slope. The significant intercept and moderate slope factor variances indicated some individual variability in both the initial level (at Wave 3) and in the growth rates of maternal depression over time. The correlation between the intercept and slope factors $(r=.28, p=.00)$ was also significant, suggesting that initial status had significant bearing on the rate of changes in growth of maternal depression.

\section{Predictors and Outcomes of Maternal Depression}

The overall model which included the predictors, mediators and child's developmental outcomes had a fit of $\chi^{2}(34)=76.23, p=.00$, $C F I=.95$, TLI $=.92$, and $R M S E A=.04$. The fit indices demonstrated a relatively good fit for the overall model. In Table 4, it is indicated that lesser the spouse was involved in childcare, lesser the mother felt effective in childcare, and severer the difficult child's temperament was and greater the postpartum depressive symptoms mothers experienced. The higher scores in mother's self-efficacy $(\beta=-.45 ; p<.00)$ and in spouse's participation $(\beta=-.11 ; p<.01)$ were negatively and in child's emotional temperament $(\beta=.10 ; p<.05)$ was positively related to the intercept factor. It means that higher the paternal involvement and maternal self-efficacy in childnurturing, and more difficult the child's emotional temperament, higher levels of maternal depression at Wave 3 were assessed. Father's participation $(\beta=-.41 ; p<.05)$ and mother's self-efficacy $(\beta=-1.09 ; \quad p<.00)$ in childcare were significantly related to the

Table 4

Results of Conditioned Model

\begin{tabular}{lcccc}
\hline & \multicolumn{2}{c}{ Intercept } & \multicolumn{2}{c}{ Slope } \\
& Estimate & $S E$ & Estimate & $S E$ \\
\hline Intercept/Slope ON: & & & & \\
Mother's Self Efficacy & $-.45^{* * *}$ & .04 & $-1.09^{* * *}$ & .17 \\
Father's Involvement & $-.11^{* *}$ & .04 & $-.41^{* *}$ & .16 \\
Mother's Wkly Work Hrs & -.00 & .00 & -.00 & .01 \\
Child's Temperament Emotion & $.10^{*}$ & .05 & -.04 & .22 \\
Mother's Parenting Style ON & $-.40^{*}$ & .20 & -.06 & .09 \\
\hline Child ON Mother's Parenting Style & Estimate & & SE & \\
\hline
\end{tabular}

$* p<.05,{ }^{* *} p<.01,{ }^{* * *} p<.001$ 


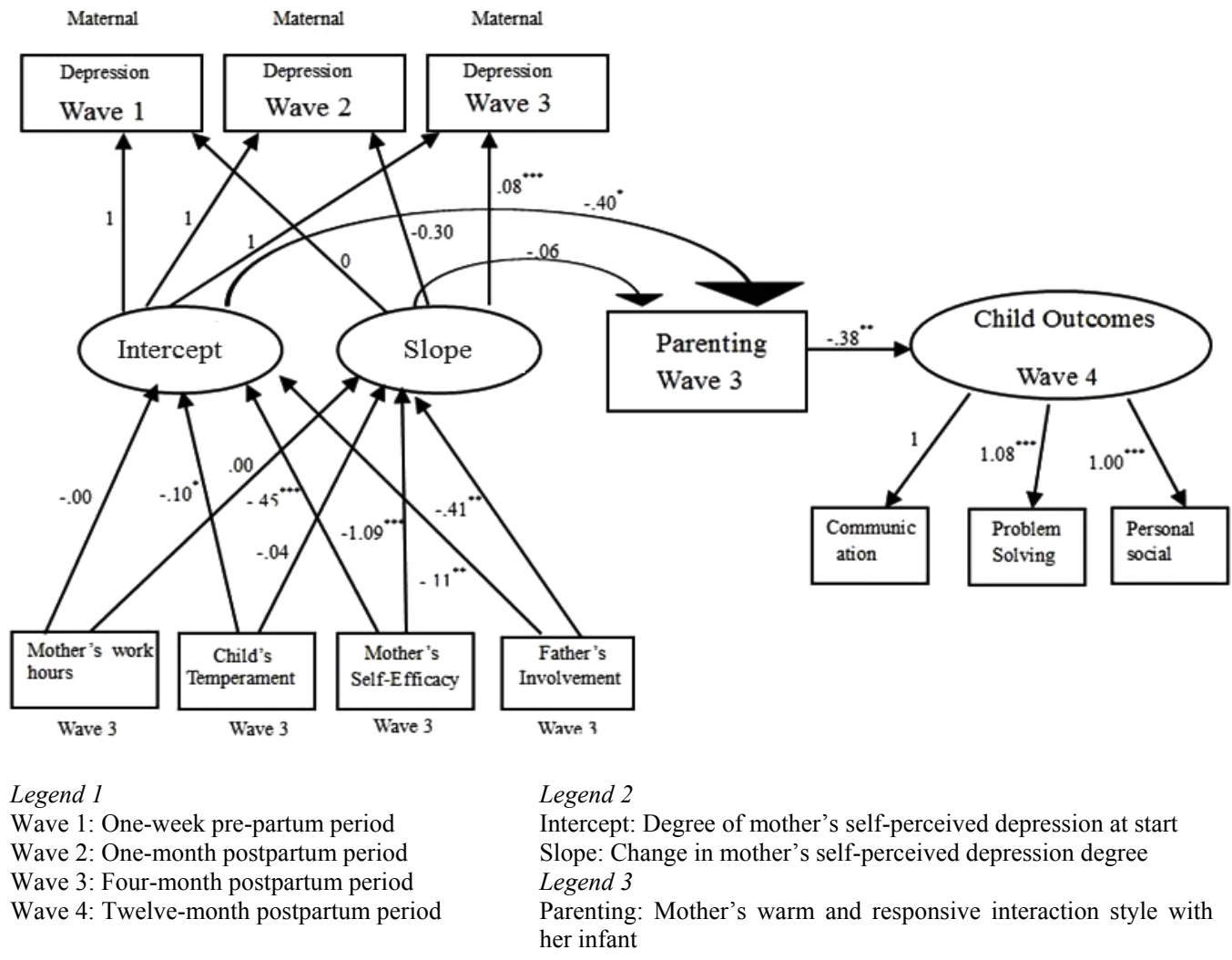

Figure 1. Latent growth model of postnatal maternal depression: Predictors and effects on Korean infants' developmental adjustment

changes of depressive symptoms, suggesting that mothers with low spousal involvement and low self-efficacy had greater increases in depression symptoms over time.

In regard to the effects of maternal depression, the intercept factor $(\beta=-.40 ; p=.04)$ of maternal depression were significantly related to mothers' parenting style at Wave 3. The intercept and parenting style had a negative relationship, meaning that higher scores in mother's depression had a lower starting point for her positive warm and responsive parenting behaviors. As for the slope and parenting style, significant association wasn't found.

Furthermore, the maternal parenting style was significantly related to child's developmental adjustment $(\beta=-.38 ; \quad p<.01)$ at Wave 4 (represented by three indicators in the model). The maternal parenting styles were significantly correlated with child's communication $(r=10$, $p<.01)$, personal social $(r=.05, p<.05)$, and problem solving $(r=.09, p<.01)$ abilities. The parenting variable significantly predicted the latent variable child $(p<.01)$. The findings suggests that mothers who had warm and responsive parenting styles had children with significantly higher levels of development in the areas of communication, personal social, and problem solving abilities at 12- months old. The overall results were as indicated in Figure 1. 


\section{Discussion}

The detailed descriptions of postpartum depressive symptoms of Korean mothers are in order. The severity of depressive symptoms, which had been reported as one of strong normative sources causing familial stress, experienced by the mothers was found to be relatively normal to low from a week prior to the birth and a month and four months postpartum. Despite the relatively low maternal depression over the three waves, Korean mothers showed a developmental pattern of decreased depressive symptoms over the first month of the child's birth but then increased on at four months to the level above that of the prenatal period. Also, less than $6.5 \%$ of mothers reported the severe degree of depressive symptoms at all three time points, having the lowest rate at the first four weeks post the birth. The rate of severe postpartum depression in this study is similar to the rate $(7.50 \%)$ of Korean mother's postpartum depression at six weeks after the birth in the study of Lee et al.'s (2010), but greatly dissimilar with $12.4 \%$ assessed after the first year (Park, Shin, Yoo, Chun, \& Moon, 2004) and 21.2\% assessed after the second year (Ahn \& Kim, 2003). These variations of the rate seem to be stemming from the time when the assessment took place. Cultural and customary practices can also influence the result: doing a month resting after the child birth; taken care by family members such as her mother, other relatives, or other hired care-takers; and checking into centers to recuperate from pregnancy and delivery. Compared to the prevalence rate of the U.S., the prevalence rate in Korea is not higher by the numbers. But, once the helpers and attention of others dissipate, and when the new mothers are on their own caring for their new babies, it is likely that they become more overwhelmed with the new tasks in front of them without any clear instruction. So the time of assessments would make great variation in depressive symptoms. Therefore, the results may imply that, unlike the first four week as the onset time suggested by DSM-V, the onset time and duration of postpartum depressive symptoms may be prolonged for mothers in Korea. Thus, future studies need to consider extending the postpartum depression period for more than four weeks.

In regard to predictors of maternal postnatal depressive symptoms, mother's self-efficacy, spousal participation in childcare, and child's emotional temperament were found to be robust in the early part of depression. The self-efficacy and spouse's support in child nurture tasks predicted the changes of depression trajectory. Mothers who perceive themselves to be highly efficient in parenting their less difficult children along with the childcare supports from their spouses at the four months, rendered less depressive symptoms in the mothers. Similarly, mothers reported a greater increase in depressive symptoms as the self-efficacy and spouse's help declined over time. Korean mothers with low parental self-efficacy (Choi et al., 2012), low parental supports from their spouses, and more irritable children, reported high levels of postpartum depressive symptoms (Moon \& Min, 2010). As for childcare supports from marital partners, they were found to function as informational, instrumental, emotional, and appraisal bases for recently birth-given-mothers (Leahy-Warren et al., 2011). Kim (1997) emphasized the role of fathers/husbands in supports for them: paternal involvement in childnurture undertook mother/wife's perception of promoted marriage quality that generated stability, acceptance, endurance, and warmth in the family. The spouse's involvement provided social and emotional supports as well as physical supports, enhancing the marital relationship to ease and overcome PPDS.

The emotional temperament of under one-year olds assessed by Buss and Plomin's (1987) scale was reported to be associated with anxiety or fear (Lee et al., 2010), causing parental stress. Among emotional, active, and social temperaments, the emotional temperament has been reported to be most related to mother's perceived parental stress (Shin, 1996). Overall, our results are in keeping with those reported by the previous literatures in these regards. It can be, however, viewed as maternal self-efficacy is a 
buffering factor whereas child's characteristics of being easily provoked to cry and agitated is a risk factor in explaining variances of maternal postpartum depressive symptoms.

The mother's weekly work-hour-factor turned out to be an insignificant factor for the trajectories of mother's perceived postpartum depressive symptoms. Many studies proposed that, compared to house-wife, employed mothers have been identified to be more at risk for PPDS (Bloch et al., 2005; Taherifard, Delpisheh, Shirali, Afkhamzadeh, \& Veisani, 2013). However, this study evidenced no significant relationship between mother's work hours and the trajectories of her postpartum-depressive symptoms, but the relationship had the negative direction. This result can be understood in the light of Korean Employment Law Article 74 that requires mothers with whether paid or nonpaid maternity-leaves returned to work by fourmonth-postpartum (Ministry of Employment \& Labor, 2001). Most mothers who were previously employed would be going through difficulty time adjusting to the recently acquired primary childcare role and back to their previous jobs. The mothers with greater maternal employment hours would perceive less depressive symptoms, which may be explained by being able to obtain an alternative means of support for her infant to fill her absence while at work to overcome the adjustment difficulty. According to Leahy-Warren and colleagues (2011), the persons most frequently identified by mothers as having provided support were their own mothers, husbands/partners and sisters. Haslam et al. (2006) also reported that women identified their maternal mother as the parental person who mostly provided them with all four types of supports, leading to vicarious infant care experiences and verbal encouragement. This hypothesis seemed reasonable in this study that among 297 families identified as receiving alternative care-person's support for their infants, $79.2 \%$ of families had children's grandmothers as their caretakers supporting the mothers. Considering that the number of working mothers added up to 451 in the sample, more than half of these mothers had either their mothers-in-law or their own mothers to take care of their infants. This figure would increase when the number of families utilizing child-care institutions was included. Therefore, closer attentions on alternative supporters of childcare, other than married partners, would be of great value for the follow-up study to investigate the effects of mother's working hours on their PPDS

The significant association between the beginning of the trajectories of maternal depressive symptoms and maternal parenting style at four months was confirmed. The high maternal depressive symptom at the starting point was related to less warm and less responsive parenting behaviors of mothers at four months. At infancy when physical contacts with mothers became the key to optimal development of children (Hertenstein, 2002), depressed mothers tended to pass on their unstable psychological states through their harmful physical contacts such as abrupt, overstimulating, controlling, and poking and tickling behaviors (Kim \& Kwak, 2005; Beebe et al., 2010). Moon and Oh (1995) explained that depressed mothers orient less to their young children and interact more abnormally with them. However, father's supportive involvement at this time has been reported to reduce the adverse long-term effects of maternal depression during a child's infancy on later child behavior problems (Mezulis, Hyde, \& Clark, 2004). When fathers were supportive and encouraging of their spouses' parenting, mothers were more patient, flexible, emotionally responsive, sensitive, and available to their infants and young children (Belsky, 1984; Snarey, 1993), and this tends to enhance the quality of the mother-child relationship (Lamb, 1997). On the other hand, inadequate social or paternal supports were associated with higher rates of depression and hostility, which in turn were related to mothers' use of ineffective parenting practices (Simons, Lorenz, Wu, \& Conger, 1993). In sum, the results of this study suggest spousal involvement in child care having significant positive effects on maternal PPDS through supportive partnership in marriage or supportive parenting per say (Simons et al., 1993), thus facilitating 
developmental outcomes for their children. Comparative analysis would be also of importance in order to examine the differences in maternal PPDS via the support provided by the husband/partner in marriage vs. alternative family (grandparent, aunt or other caring relative) vs. hired worker. For example, the subject that had equal amount of time spent to take care of infant by a hired care taker could be compared to that by the father/husband and by the partner in the same sex marriage.

The significant link between parenting behaviors of mothers with PPDS and their infants' adjustment has been well established in the literature (e.g., Molfese et al., 2010). Mothers with PPDS typically interact with their infants and young children through two interactive patterns, intrusiveness or withdrawal (Cohn \& Tronick, 1989). Intrusive mothers display a hostile affect, and disrupt the infant's activity. Then, the infants experience anger, turn away from the mother to limit her intrusiveness and internalize an angry and protective style of coping. Withdrawn mothers are disengaged, unresponsive, and affectively flat and do little to support the infant's activity. The infants are unable to cope or self-regulate this negative state, and develop passivity, withdrawal and selfregulatory behaviors (Hart, Field, de Valle, \& Pelaez-Nogueras, 1998). On the other hand mothers' warmth, flexibility, responsiveness, and expressiveness are especially important for infants to make sense of and understand objects in the world, express and read basic human emotions and more for the first time (Landry, 2008; Landry et al, 2006). Findings from the present study was congruent with these previous studies that mothers' warm and responsive parenting behaviors having significant effects on young children's development of communication, problem solving and personal-social ability.

In conclusion, mothers' PPDS could be helped greatly by boosting her perception of selfefficacy in caring for her infant. Mothers raising difficult infants with husbands who participated well in childcare demonstrated less depressive mood. The initiation of depressive mood, during the given periods, determined the degree of warm and responsive maternal parenting implemented. Finally, the warmer and more responsive parenting of mothers resulted in better development in areas of social, cognitive and communication, and healthier infant growth. Intrinsic merit of the study included national profiling of PPD in Korean mothers considering the complex interacting factors and the statistically represented data that may have been influenced by the unique cultural and customary practices.

The present study included some limitations employing a survey questionnaire to determine PPD. The diagnosis of PPD was implemented using The Kessler's Depression Scale, a selfreport rating scale, rather than a clinicianadministered structured diagnostic interview. Also limited was the assessment at the first month obtained through telephone calls which missed out on direct observation of the subjects, her environment and infant. Moreover, variables of family resources, child's characteristics, and parenting styles were all limitedly reported by mothers without secondary confirmation. The employment of standardized and discriminating direct observational techniques would be highly useful for the future research as would be for comparative analyses described before.

Despite the shortcomings of the national panel study, the following implications can be derived from this study: (1) The onset of postpartum depressive symptoms (PPDS) might need to be prolonged beyond the first four weeks as described in DSM-V due to customary differences in South Korea; (2) It enhanced the understanding of the determinants of the trajectories of Korean mother's PPDS in relations to existing Belsky's processing model of parenting; (3) It provided fundamental knowledge on which awareness, preventive and interventional programs might be built to facilitate Korean mothers with severe PPDS for the promotion of optimal early development of Korean children. The programs should involve educating both spouses and other familial supporters along with expecting mothers in order to establish informational, instrumental, emotional, and appraisal bases for the mothers to 
rely on the process of overcoming the PPDS.

\section{References}

Ahn, Y. M., \& Kim, J. H. (2003). A comparison study of normal and underweight infantgroups on maternal self-esteem, postpartum depression, and family supports. Journal of Nursing in Korea, 16(1), 580-590.

American Psychiatric Association. (2012). Diagnostic and statistical manual of mental disorder (5th ed.): DSM-V. Washington, D.C.: Author.

Beck, C. T. (2001). Predictors of postpartum depression: An update. Nursing Research, 50(5), 275-285.

Beebe, B., Jaffe, J., Buck, K., Chen, H., Cohen, P., Feldstein, S., \& Andrews, H. (2008). Six-week postpartum maternal depressive symptoms and 4-month-infant self-and interactive contingency. Infant Mental Health Journal, 29(5), 442-472.

Beebe, B., Jaffe, J., Markese, S., Buck, K., Chen, H., Cohen, P., Bahrick, L., Andrew, H., \& Feldstein, S. (2010). The origins of 12-month attachment: A microanalysis of 4-month mother-infant interaction. Attachment \& Human Development, 12(1), 3-141.

Belsky, J. (1984). The determinants of parenting: A process model. Child Development, 55, 8396.

Bloch, M., Rotenberg, N., Koren, D., \& Klein, E. (2005). Risk factors associated with the development of postpartum mood disorders. Journal of Affective Disorders, 88(1), 9-18.

Bloomfield, L., Kendall, S., Applin, L., Attarzadeh, V., Dearnley, K., Edwards, L., Hinshelwood, L., Lloyd P., \& Newcombe, T. (2005). A qualitative study exploring the experiences and views of mothers, health visitors and family support centre workers on the challenges and difficulties of parenting. Health Social Care Community, 13(1), 46-55.

Boivin, M., Perusse, D., Dionne, G., Saysset, V., Zoccolillo, M., Tarabulsy, G. M., Tremblay, N., \& Tremblay, R. E. (2005). The geneticenvironmental etiology of parents; Perceptions and self-assessed behaviours toward their 5month old infants in a large twin and singleton sample. Journal of Child Psychology and Psychiatry and Allied Disciplines, 46, 612-630. Bornstein, M. H., Tamis-LeMonda, C. S., Pascual, L., Haynes, M. O., Painter, K. M., Galperin, C. Z., \& Pecheux, M. G. (1996). Ideas about parenting in Argentina, France, and the United States. International Journal of Behavioral Development, 19(2), 347-367.

Bowen, A., \& Muhajarine, N. (2006). Prevalence of antenatal depression in women enrolled in an outreach program in Canada. Journal of Obstetric, Gynecologic, and Neonatal Nursing, 35(4), 491-8.

Buss, A. H., \& Plomin, R. (1984). Temperament: Early developing personality traits. Hillsdale, NJ: Erlbaum.

Campbell, S., Cohn, J., \& Meyers, J. (1995). Depression in first-time mothers: Motherinfant interaction and depression chronicity. Developmental Psychology, 31, 349-357.

Cho, B. H., Shin, N. R., Ahn, J. J., Lee, J. L., Choi, Y. K., Song, S. Y., Kim, J. Y., \& Kim, Y. W. (2009). Research report 2009-12. Panel Study of Korean Children (PSKC) by Korea Institute of Child Care and Education (KICCE).

Cho, Y. S. (1998). The effects of the husband's emotional support on the prevention of postpartum depression: Using an experiential technique intervention. Doctoral Dissertation. Ewha Women' University. South Korea.

Choi, H. J. (2012). The analysis of economical status of Korean households. A symposium at Seoul University.

Choi, I. A., Lee, K. S, Shin, Y. J., \& Park, J. A. (2012). Mental health of mothers and their infant depending on degree of mothers' preand post-natal depression. The Korean Journal of Developmental Psychology, 25(3), 125-148.

Choi, S. Y., Kim, E. J., Ryu, E., Chang, K. O., \& Park, M. N. (2012). Postpartum depression and parental self-efficacy: A comparison of native Korean and Vietnamese immigrant mothers in Korea. Journal of Transcultural Nursing, 23(2), 181-187. 
Cohn J. F., \& Tronick, E. (1989). Specificity of infants' response to mothers' affective behavior. Journal of American Academy of Child Adolescence Psychiatry, 28, 242-248.

Coleman, P. K., \& Karraker, K. H. (2000). Parenting self-efficacy among mothers of school-age children; Conceptualization, measurement, and correlates. Family Relations, 49, 13-24.

Conenwett, L. R., \& Wilson, W. K. (1983). Stress, social support and the transition to fatherhood. Nursing Research, 30(4), 196-200.

Cooper, P., \& Murray, L. (1995). Course and recurrence of postnatal depression: Evidence for the specificity of the diagnostic concept. British Journal of Psychiatry, 166, 191-195.

Cornish, A. M., McMahon, C. A., Ungerer, J. A., Barnett, B., Kowalenko, N., \& Tennant, C. (2005). Postnatal depression and infant cognitive and motor development in the second postnatal year: The impact of depression chronicity and infant gender. Infant Behavior \& Development, 28, 407-417.

Cutrona, C. E., \& Troutman, B. R. (1986). Social support, infant temperament and parenting self-efficacy: A mediational model of postpartum expression. Child Development, 57, 1507-1518

Davis, E. P., Townsend, E. L., Gunnar, M. R., Georgieff, M. K., Guiang, S. F., Ciffuentes, R. F., \& Lussky, R .C. (2004). Effects of prenatal betamethasone exposure on regulation of stress physiology in healthy premature infants. Psychoneuroendocrinology, 29, 1028-1036.

Dodge, K. A. (1990). Developmental psychopathology in children of depressed mothers. Developmental Psychology, 26(1), 36.

Downey, G., \& Coyne, J. C. (1990). Children of depressed parents: An integrative review. Psychological Bulletin, 108(1), 50-76.

Erdwins, C., Buffardi, L., Casper, W., \& O'Brien, A. (2001). The relationship of women's role strain to social support, role satisfaction and self-efficacy. Family Relations, 50, 230-238.

Field, T., Healy, B., Goldstein, S., \& Guthertz, M. (1990). Behavior-state matching and synchrony in mother-infant interaction of nondepress versus depressed dyads. Developmental Psychology, 26, 7-14.

Field, T. (1995). Infants of depressed mothers. Infant Behavior \& Development, 18(1), 1-13.

Fletcher, R. (2009). Promoting infant well-being in the context of maternal depression by supporting the father. Infant Mental Health Journal, 30(1), 95-102.

Häggman-Laitila, A. (2003). Early support needs of Finnish Families with small children. Journal of Advanced Nursing, 41, 595-606.

Halbreich, U., \& Karkun, S. (2006). Crosscultural and social diversity of prevalence of postpartum depression and depressive symptoms. Journal of Affective Disorder, 91, 97-111.

Hanington, L., Ramchandani, P., \& Stein, A. (2010). Parental depression and child temperament: Assessing child to parent effects in a longitudinal population study. Infant Behavioral Development, 33(1), 88-95.

Han, Y. M., \& Kwak, H. K. (2004). Lowbirthrate and social participation of Korean Women. Korean Journal of human ecology, 13, 29-40.

Haslam, D., Pakenham, K., \& Smith, A. (2006). Social supports and postpartum depressive symptomatology: The mediating role of maternal self-efficacy. Infant Mental Health Journal, 27, 276-291.

Hart, S., Field, T., del Valle, C., \& PelaezNogueras, M. (1998). Depressed mothers' interactions with their one-year-old infants. Infant Behavior Development, 21, 519-525.

Hay, D. F., Pawlby, S., Waters, C. S., \& Sharp, D. (2008). Antepartum and postpartum exposure to maternal depression: different effects on different adolescent outcomes. Journal of Child Psychology and Psychiatry, 49, 1079-1008.

Heo, K. H., Squires, J., Lee, S. Y., \& Lee, J. S. (2006). K-ASQ (Korean Version of Ages \& Stages Questionnaires): Parent-report form of monitor for infants. Seoul Handicap Center.

Hertenstein, M. J. (2002). Touch: Its communicative functions in infancy. Human Development, 45, 70-94. 
Jung, M. H., \& Kim, G. I. (2005). A study on the relationship among prenatal emotional status, preparation for delivery, postpartum social support and postpartum blues. Korean Journal of Women Health Nursing, 11(1), 38-45.

Kang, H. K. (1993). Parental stress of employed mothers with children under three year-old: Focused on mothers' perception of parental roles and support systems. Doctoral Dissertation. Kyung Hee University. South Korea.

Kang, H. R., \& Cho, S. Y. (2001). Antecedents and outcomes of work-family conflict of married working women. Journal of Korean Psychology, 6(1), 23-42.

Kessler, R. C., Andrew, G., Cople, L. J., Hiripi, E., Mroczek, D. K., Normand, S. -L. T., Walters, E. E., \& Zaslavsky, A. (2002). Short screening scales to monitor population prevalence and trends in nonspecific psychological distress. Psychological Medicine, 32(6), 959-976.

Kim, H. J. (1997). Factors influencing father's involvement in childcare and fathering practices (Master's thesis). Ewha Women's University. South Korea.

Kim, H. J. (2007). Maternal postpartum depression of the employed (Master's thesis). Ewha Women's University. South Korea.

Kim, K. E., \& Jang, Y. G. (2008). A hermeneutics phenomenological study on working mother's experiences of rearing their firstborns. Korean Qualitative Research Center, 9(1), 31-43.

Kim, S. C., \& Kwak, K. J. (2005). On the depression, anxiety, parenting stress, feeling of touch, and self-concept: The relations among, mothers' touch pattern and mother's internal states, and touch situations in infants at 6 months. The Korean Journal of Developmental Psychology, 18(2), 1-21.

Kitamura, T., Sugawara, M., \& Shima, S. (1999). Childhood adversities and depression: II. Parental loss, rearing, and symptom profile of antenatal depression. Archives of Women's Mental Health, 1, 175-182.

Lamb, M. E. (1997). Fathers and child development: An introductory overview and guide. In M. E. Lamb (Ed.), The role of the father in child development (3rd ed., pp. 1-18). New York: John Wiley \& Sons, Inc.

Landry, S. H. (2008). The role of parents in early childhood learning. Tremblay, RE.; Barr, RG.; Peters, $R D$. Retrieved from http://www.childencyclopedia.com/documents/LandryANGxp. pdf.

Landry, S. H., Smith, K. E., \& Swank, P. R. (2006). Responsive parenting: Establishing early foundations for social, communication, and independent problem solving. Developmental Psychology, 42(4), 627-642.

Leahy-Warren, P. (2005). First-time mothers' social support and confidence in infant care. Journal of Advanced Nursing, 50, 479-488.

Leahy-Warren, P., McCarthy, G., \& Corcoran, P. (2011). First-time mothers: Social support, maternal parental self-efficacy and postnatal depression. Journal of Clinical Nursing, 21, 388-397.

Lee, K. S., Chung, Y. K., Lee, J. Y., \& Gi, D. Y. (2010). Face-to-face still face paradigm of depressed and nondepressed mother-infant pairs at six-to-eight months. The Korean Psychological Association: Annual Conference Dissertations, 306-307.

Lee, J. Y., Lee, K. S., Chung, Y. K., \& Shin, Y. J. (2011). An analysis of interactions between mothers with postpartum depression tendencies and their infants. Korean Association of Child Studies, 32(3), 203-220.

Lifeman, J. (2002). The effect of maternal depressive symptomatology on maternal behaviors associated with child health. Health Education and Behavior, 29 (5), 506-607.

Luoma, M. D., Tamminen, T., Kaukonen, P., Laippala, P., Puura, K., Salmelin, R., \& Almqvist, F. (2001). Longitudinal study of maternal depressive symptoms and child wellbeing. Journal of American Academy of Child \& Adolescent Psychiatry, 40(12), 1367-1374.

McLearn, K. T., Miakovitz, C. S., Strobiao, D. M., Marks, E., \& Hou, W. (2006). Maternal depressive symptoms at 2 to 4 months postpartum and early parenting practices. Archives of Pediatric \& Adolescent Medicine, 160, 279-284. 
Mainieri, T. \& Grodsky, M. (2006). The panel study of income dynamics - Child development supplement. User guide supplement for CDS-I. Retrieved from http//psidonlinejsr.umich.edu/ CDS/CDS1_UGSupp.pdf.

Meyers, S. A. (1999). Mothering in context ecological determinants of parent behavior. Merrill-Palmer Quarterly, 45, 332-357.

Mezulis, A. H., Hyde, J. S., \& Clark, R. (2004). Father involvement moderates the effect of maternal depression during a child's infancy on child behavior problems in kindergarten. Journal of Family Psychology, 18(4), 575-588.

Ministry of Employment and Labor of Korea. (2001). Laws for materiality-leaves. Retrieved from http://www.moel.go.kr/

Ministry of Health \& Welfare. (2013). Korea national survey on childcare supports. Retrieved from http://www.mw.go.kr/

Molfese, V. J., Rudalsill, K. M., Beswick, J. L., Jacobi-Vessels, J. L., Ferguson, M. C., \& White, J. M. (2010). Infant temperament, maternal personality, and parenting stress as contributors to infant development outcomes. Merrill-Palmer Quarterly, 56(1), 49-79.

Moon, K. J., \& Oh, K. J. (1995). The relations between maternal depression and child's maladjustment. The Korean Journal of Clinical Psychology, 14(1), 41-55.

Moon, K. J., \& Oh, K. J. (1995). The relations between maternal depression and child's maladjustment. The Korean Journal of Clinical Psychology, 14(1), 41-55.

Moon, Y. K., \& Min, H. S. (2010). Predictors of infants parents' self-efficacy. The First Forum for Korean Child Panel, KICCE.

Murray, L., \& Cooper, P. J. (1997). Effects of postnatal depression on infant development. Archives of Disease in Childhood, 77(2), 99101.

Muthén, L. K., \& Muthén, B. O. (1998). Statistical analysis with latent variables. Mplus User's guide, 1998-2012.

NHS (2012). Postnatal depression-Symptoms. Retrieved from http://www.nhs.uk/ Conditions/ Postnataldepression/Pages/Symptoms.aspx

O'Hara, M. W., \& McCabe, J. E. (2013). Postpartum depression: Current status and future directions. Annual Review of Clinical Psychology, 9, 379-407.

Park, Y. J., Shin, H. J., Yoo, H. S., Chun, S. H., \& Moon, S. H. (2004). Predictors of postpartum depression. Journal of Nursing in Korea, 34(5), 722-728.

Reece, S. (1992). The parent expectations survey. Clinical Nursing Research, 1, 336-346.

Rutter, M. (1990). Commentary: Some focus and process considerations regarding the effects on children of parental depression. Developmental Psychology, 26, 60-67.

Shin, J. Y. (1996). The effect of postpartum depressive symptoms on parental stress and the infant-mother interaction (Master's thesis). Yonsei University. South Korea.

Shin, N. R. (2011). A short-term longitudinal investigation of pre- and postnatal depressive symptoms of Korean women. The Korean Home Economics Association, 49(9), 59-72.

Simons, R. L., Lorenz, F. O., Wu, C., \& Conger, R. D. (1993). Social network and marital support as mediators and moderators of the impact of stress and depression on parental behavior. Developmental Psychology, 29, 368-381.

Sohn, S. M. (2012). Parenting stress, employed and non-employed mothers' infants. The Korean Journal of Future Early Education, 19(1), 331-357.

Stone, K. (2013). Postpartum progress. Retrieved from http://www. postpartumprogress.com/ six-things-a-mothers-postpartum-depressionbill-of-rights

Stoolmiller, M. (1995). Using latent growth curve models to study developmental processes. In J. M. Gottman (Ed.), Analysis of developmental change. Mahwah, NJ: Lawrence Erlbaum Associates, Inc.

Snarey, J. (1993). How fathers care for the next generation: A four-decade study. Cambridge, MA: Harvard University Press.

Taherifard, P., Delpisheh, A., Shirali, R., Afkhamzadeh, A., \& Veisani, Y. (2013). Socioeconomic, psychiatric and materiality determinants and risks of postpartum depression in border city of Ilam, Western Iran. Hindawi Publishing Corporation 
Depression Research and Treatment, 2013, 1-7. Teti, D., \& Gelfand, D. (1991). Behavioural competence among mothers of infants in the first year: The medicational role of selfefficacy. Child Development, 65, 918-929.

Van Bakel, H. J. A., \& Riksen-Walraven, J. M. (2002). Parenting and development of oneyear-olds: Links with parental, contextual, and child characteristics. Child Development, 73(1), 256-273.

Warren, H. K., Bassett, H. H., \& Denham, S. A. (2008). Early emotional development, social cognition, and relationships with others. Zero to Three, May, 32-39.
Yoon, J. H. (2011). Predictors of postpartum depression: Prospective cohort study (Master's thesis). Busan University. South Korea.

Received: February 05, 2014 Revision Received: February 22, 2014 Accepted: February 24, 2014 